\title{
Immunosuppression for COVID-19: repurposing medicines in a pandemic
}

\section{Senthuran Shivakumar \\ Clinical pharmacology registrar, Department of \\ Clinical Pharmacology and \\ Therapeutics}

\section{Olivia C Smibert}

Infectious diseases physician, COVID Unit, Department of Infectious Diseases ${ }^{1}$

Doctoral candidate,

Sir Peter MacCallum Department of Oncology ${ }^{2}$

Doctoral candidate 3

\section{Jason A Trubiano}

Infectious diseases physician, Head of COVID Unit, Department of Infectious Diseases'

Clinical associate professor, Department of Medicine ${ }^{2}$

Postdoctoral fellow ${ }^{3}$

\section{Albert G Frauman \\ Professor and Head, Department of Clinical \\ Pharmacology and \\ Therapeutics \\ Professor of Clinical \\ Pharmacology and \\ Therapeutics ${ }^{2}$}

\section{David FL Liew}

Rheumatologist and Clinical pharmacologist, Department of Rheumatology, and Department of Clinical

Pharmacology and

Therapeutics

Doctoral candidate, Department of Medicine ${ }^{2}$

\section{${ }^{1}$ Austin Health}

2 University of Melbourne

${ }^{3}$ National Centre for Infections in Cancer, Peter MacCallum Cancer Centre Melbourne

\section{Keywords}

COVID-19,

immunosuppression interleukin-1, interleukin-6, pandemic, tocilizumab

First published 17 June 2020 Aust Prescr 2020;43:106-7 https://doi.org/10.18773/ austprescr.2020.037
It might seem paradoxical to suggest

immunosuppression could play a role in managing COVID-19. The seemingly logical therapeutic option for this disease would be an antiviral. Unfortunately, repurposing antiviral therapies has proven disappointing so far, and evidence to support their routine use in COVID-19 is currently lacking.-4

While the current standard of care for most people with COVID-19 is supportive, a subset of patients become severely unwell with a potentially lifethreatening hyperinflammatory state called cytokine release syndrome. ${ }^{5}$ This clinical state is difficult to predict in advance. When it occurs it is characterised by rapidly worsening multiorgan dysfunction including respiratory failure and a clinically distinctive coagulopathy involving immunothrombosis of the pulmonary vasculature. ${ }^{6}$ Antigens presented by infected cells activate both the innate and adaptive immune systems. The uncontrolled upregulation of immune cells leads to a surge of proinflammatory cytokines including interleukin- 6 and interleukin-1. This in turn increases vascular permeability and inflammatory cell recruitment into lung parenchyma causing acute lung injury and subsequent respiratory failure. As a myriad of proinflammatory molecules and inflammatory markers are involved in both the typical immune response to infection and this hyperinflammatory and hypercoagulable state, the key drivers of inflammation and mortality in severe COVID-19 are contentious. As such, the benefit of treating this hyperinflammatory state has not yet been completely established in COVID-19.

In patients with severe COVID-19, there is significant mortality in the second week of disease, ${ }^{7,8}$ despite many studies describing a progressive fall in viral count. 910 This may partially explain the lack of success with antivirals. In this situation, immune-driven damage, such as cytokine release syndrome, may be what is driving mortality. Therefore early recognition and prompt initiation of immunosuppression may benefit these patients.

Cytokine release syndrome is a known phenomenon, and pathophysiologically similar syndromes exist in autoimmune diseases such as systemic juvenile idiopathic arthritis and adult onset Still's disease. It is also encountered as a complication of chimeric antigen receptor T-cell (CAR T-cell) therapy used for haematological malignancies.
Interleukin-6 and interleukin-1 driven pathways have a central role in cytokine release syndrome associated with COVID-19 and in other previously recognised cytokine release syndromes. Therapies targeting these pathways include tocilizumab (an interleukin- 6 receptor antagonist) and anakinra (an interleukin-1 receptor antagonist). These are both registered by the Therapeutic Goods Administration (TGA) for cytokine release syndrome-like autoimmune conditions such as systemic juvenile idiopathic arthritis. Anakinra has previously been used in the treatment of macrophage activation syndrome, a cytokine release syndrome associated with autoimmune conditions." Tocilizumab is registered for the management of cytokine release syndrome secondary to CAR T-cell therapy. The possibility of adopting these immunosuppressive therapies in COVID-19 is supported by early evidence from observational studies. ${ }^{12}$ However, these drugs need the same caution as any off-label and experimental prescribing in COVID-19 until they are validated in clinical trials. ${ }^{13-15}$

Not all immunosuppressive drugs hold the same promise. While systemic corticosteroids are effective immunosuppressants, previous and current outbreaks suggest that their broader physiological effects lead to uncertain benefit and potential harm. ${ }^{16-18}$ Accordingly, they are avoided in routine care unless for a recognised indication. Colchicine has also generated interest due to its effect on the inflammasome-mediated interleukin-1 beta pathway which is part of the innate immune response. However, its use in COVID-19 remains unproven. ${ }^{19}$ Baricitinib, a Janus kinase inhibitor used for rheumatoid arthritis, was identified through a machine-learning exercise as potentially reducing viral entry into cells in COVID-19, but currently has no established use in cytokine release syndrome. ${ }^{20}$

Some important distinctions exist between the rational repurposing of immunosuppression in COVID-19 and other widely discussed experimental therapies. ${ }^{21}$ Tocilizumab is already part of the evidence-based management of CAR T-cellinduced cytokine release syndrome, ${ }^{6,22}$ a condition that shares pathological similarities. In contrast, proposed antiviral strategies that include chloroquine, hydroxychloroquine, and ivermectin are reliant on novel mechanisms of action and low-quality evidence, while raising significant safety concerns. ${ }^{23,24}$ 
COVID-19 poses a multifaceted threat requiring a multimodal and stratified treatment approach, possibly transitioning from virus-targeted approaches in the early state of disease to immunomodulation in late-onset immune-mediated disease. The example of interleukin-6 and interleukin-1 inhibition demonstrates that a cohesive and considered approach towards offlabel prescribing in COVID-19 is needed. This should be used in consultation with relevant subspecialties and drug and therapeutic committees. ${ }^{21}$ Decision making should also include patients and their families. ${ }^{25}$ As it is not yet standard of care, reporting safety and efficacy outcomes as part of clinical trials is highly desirable. With such measures, repurposed medicines can be appropriately recruited into the pandemic fight without defying sensible prescribing. ${ }^{21,25}<$

\section{Conflict of interest: none declared}

\section{REFERENCES}

1. Stockman LJ, Bellamy R, Garner P. SARS: systematic review of treatment effects. PLoS Med 2006:3:e343. https://doi.org/ 10.1371/journal.pmed.0030343

2. Cao B, Wang Y, Wen D, Liu W, Wang J, Fan G et al A trial of lopinavir-ritonavir in adults hospitalized with severe Covid-19. N Engl J Med 2020;382:1787-99. https://doi.org/10.1056/ NEJMoa2001282

3. Centers for Disease Control and Prevention. Influenza antiviral medications: summary for clinicians. Reviewed 2020 Jan 15. https://www.cdc.gov/flu/professionals/antivirals/ summary-clinicians.htm [cited 2020 Jun 9]

4. Wang Y, Zhang D, Du G, Du R, Zhao J, Jin Y, et al. Remdesivir in adults with severe COVID-19: a randomised, double-blind, placebo-controlled, multicentre trial. Lancet 2020;395:1569-78. https://doi.org/10.1016/ S0140-6736(20)31022-9

5. The Novel Coronavirus Pneumonia Emergency Response Epidemiology Team. Vital surveillances: The epidemiological characteristics of an outbreak of 2019 novel coronavirus diseases (COVID-19) - China, 2020. China CDC Weekly 2020;2:113-22. http://weekly.chinacdc.cn/en/article/ doi/10.46234/ccdcw2020.032

6. McGonagle D, O'Donnell JS, Sharif K, Emery P, Bridgewood C. Immune mechanisms of pulmonary intravascular coagulopathy in COVID-19 pneumonia. Lancet Rheumatol 2020 May 07 [Epub ahead of print] https://doi.org/10.1016/S2665-9913(20)30121-1

7. Siddiqi HK, Mehra MR. COVID-19 illness in native and immunosuppressed states: a clinical-therapeutic staging proposal. J Heart Lung Transplant 2020;39:405-7. https://doi.org/10.1016/j.healun.2020.03.012

8. Huang C, Wang Y, Li X, Ren L, Zhao J, Hu Y, et al. Clinical features of patients infected with 2019 novel coronavirus in Wuhan, China. Lancet 2020;395:497-506. https://doi.org/ 10.1016/S0140-6736(20)30183-5

9. Joynt GM, Wu WK. Understanding COVID-19: what does viral RNA load really mean? Lancet Infect Dis 2020;20:635-6. https://doi.org/10.1016/S1473-3099(20)30237-1

10. Zou L, Ruan F, Huang M, Liang L, Huang H, Hong Z, et al. SARS-CoV-2 viral load in upper respiratory specimens of infected patients. N Engl J Med 2020;382:1177-9. https://doi.org/10.1056/NEJMc2001737

11. Monteagudo LA, Boothby A, Gertner E. Continuous intravenous anakinra infusion to calm the cytokine storm in macrophage activation syndrome. ACR Open Rheumato 2020;2:276-82. https://doi.org/10.1002/acr2.11135

12. Luo P, Liu Y, Qiu L, Liu X, Liu D, Li J. Tocilizumab treatment in COVID-19: a single center experience. J Med Virol 2020 Apr 6 [Epub ahead of print]. https://doi.org/10.1002/jmv.25801

13. Davis JS, Ferreira D, Denholm JT, Tong SY. Clinical trials for the prevention and treatment of coronavirus disease 2019 (COVID-19): the current state of play. Med J Aust 2020 Apr 27 [Preprint]. www.mja.com.au/journal/2020/clinicaltrials-prevention-and-treatment-coronavirus-disease-2019covid-19-current
14. Coombes I, Markwell A, Kubler P, Redmond AM, McGurk G Roberts JA. Principles of ethical prescribing for self and others: hydoxychloroquine in the COVID-19 pandemic. Aust Prescr 2020;43:76-7. https://doi.org/10.18773/ austprescr.2020.030

15. Roberts DM, Bennett A. COVID-19 and the quality use of medicines: evidence, risks and fads. Aust Prescr 2020;43:78-80. https://doi.org/10.18773/austprescr.2020.031

16. Arabi YM, Mandourah Y, Al-Hameed F, Sindi AA, Almekhlafi GA, Hussein MA, et al.; Saudi Critical Care Trial Group. Corticosteroid therapy for critically ill patients with middle east respiratory syndrome. Am J Respir Crit Care Med 2018;197:757-67. https://doi.org/10.1164/rccm.201706-11720C

17. Veronese N, Demurtas J, Yang L, Tonelli R, Barbagallo $M$ Lopalco P, et al. Use of corticosteroids in coronavirus disease 2019 pneumonia: a systematic review of the literature. Front Med (Lausanne) 2020;7:170. https://doi.org/10.3389/ fmed.2020.00170

18. Russell CD, Millar JE, Baillie JK. Clinical evidence does not support corticosteroid treatment for 2019-nCoV lung injury. Lancet 2020;395:473-5. https://doi.org/10.1016/ S0140-6736(20)30317-2

19. Deftereos S, Giannopoulos G, Vrachatis DA, Siasos G, Giotaki SG, Cleman M, et al. Colchicine as a potent antiinflammatory treatment in COVID-19: can we teach an old dog new tricks? Eur Heart J Cardiovasc Pharmacother 2020 Apr 27 [Epub ahead of print]. https://dx.doi.org/ 10.1093/ehjcvp/pvaa033

20. Richardson P, Griffin I, Tucker C, Smith D, Oechsle O, Phelan A, et al. Baricitinib as potential treatment for 2019nCoV acute respiratory disease. Lancet 2020;395:e30-1. https://doi.org/10.1016/S0140-6736(20)30304-4

21. Council of Australian Therapeutic Advisory Groups. Rethinking medicines decision-making in Australian hospitals: guiding principles for the quality use of off-label medicines. Sydney: CATAG; 2013. http://www.catag.org.au/ rethinking-medicines-decision-making [cited 2020 Jun 9]

22. Le RQ, Li L, Yuan W, Shord SS, Nie L, Habtemariam BA, et al. FDA approval summary: tocilizumab for treatment of chimeric antigen receptor T cell-induced severe or life-threatening cytokine release syndrome. Oncologist 2018;23:943-7. https://doi.org/10.1634/ theoncologist.2018-0028

23. National COVID-19 Clinical Evidence Taskforce. Caring for people with COVID-19. Living guidelines. 2020 Jun 9. https://covid19evidence.net.au [cited 2020 Jun 9]

24. Taccone FS, Gorham J, Vincent JL. Hydroxychloroquine in the management of critically ill patients with COVID-19: the need for an evidence base. Lancet Respir Med 2020;8:539-41. https://doi.org/10.1016/S2213-2600(20)30172-7

25. Day R. Off-label prescribing. Aust Prescr 2013;36:182-3. https://doi.org/10.18773/austprescr.2013.075 